\title{
OUTBREAK OF SCRUB TYPHUS IN MEWAR REGION
}

\section{Aditya Vyas*}

\section{Akash Lakum}

\section{Āshish Bansal}

\section{Gaurav Sharma}

$3^{\text {rd }}$ year resident, Assistant Professor, Department of General Medicine, Geetanjali medical college and hospital, Udaipur-313002. ${ }^{*}$ Corresponding Author

$3^{\text {rd }}$ year resident, Assistant Professor, Department of General Medicine, Geetanjali medical college and hospital, Udaipur-313002.

$3^{\text {rd }}$ year resident, Assistant Professor, Department of General Medicine, Geetanjali medical college and hospital, Udaipur-313002.

Assistant Professor, Department of General Medicine, Geetanjali medical college and hospital, Udaipur-313002.

\section{ABSTRACT Scrub typhus is a zoonotic disease caused by Orientia tsutsugamushi, an obligate intracellular gram-} negative bacterium. It is transmitted via the larval stage of trombiculid mites (chigger, a primary reservoir) $)^{1}$. It is prevalent across southern and eastern India including Rajasthan. This study reports the outbreak of scrub typhus in Mewar region of Rajasthan in 2019. Methods: 50 scrub typhus patients were studied at Geetanjali Medical College and Hospital, Udaipur, Rajasthan. Scrub typhus was diagnosed by enzyme linked immunoassay for scrub typhus along with routine blood tests, and ultrasonography of abdomen. Results: In our study, fever was the most common symptom seen in all patients $(100 \%)$, followed by breathlessness $(80 \%)$ and the most common sign is jaundice (76.6\%). Two thirds of the patients had multi-system involvement. 4 deaths occurred in the study. Conclusion: Our study denotes the emergence of scrub typhus in Mewar region presenting as acute febrile illness with or without eschar. It should be considered as a differential diagnosis with high index of suspicion for acute febrile illness in patients from this region, as early diagnosis and intervention may reduce mortality.

\section{KEYWORDS : Scrub typhus, Mewar.}

\section{INTRODUCTION:}

Orientia tsutsugamushi belongs to the Rickettsiae group of obligately intracellular, gram-negative coccobacilli and short bacilli. O. tsutsugamushi differs substantially from Rickettsia species both genetically and in cell wall composition (i.e., it lacks lipopolysaccharide). It persists by transovarial transmission in trombiculid mites ${ }^{1}$. Chiggers (only stage to transmit disease) inoculate organisms into the skin.

Scrub typhus is an endemic and a re-emerging disease in eastern and southern Asia. In high-risk areas the prevalence could be $>3 \%$ of the population. Immunity is not long lasting and the organism exhibits remarkable antigenic diversity ${ }^{2}$. Approximately one million cases are reported annually ${ }^{3}$.

The illness could be self-limiting to fatal. Incubation period is 6-21 days (average 10-12 days). Onset is characterized by fever, headache, myalgia, associated with cough, nausea, diarrhea and vomiting. The peculiar eschar at the bite site, lymphadenopathy and maculopapular rash may or may not be seen ${ }^{4}$. It is considered a differential diagnosis in patients with acute febrile illness which is associated with hepatic dysfunction, thrombocytopenia, renal impairment, altered sensorium, pneumonitis or $\operatorname{ARDS}^{5}$. Other gastro-intestinal manifestations reported include acute acalculous cholecystitis, duodenal ulcer perforation, peritonitis and gastric ulceration and pancreatitis ${ }^{6}$. The mortality rate for untreated patients is $7-30 \%$ which can be prevented by early recognition of this treatable disease ${ }^{7}$.

\section{AIMS AND OBJECTIVES}

1. To identify scrub typhus as an important aetiological agent of acute febrile illness in Mewar region.

2. To describe the clinical features, manifestations and complication in patients diagnosed with scrub typhus.

3. To know about its atypical clinical presentations.

\section{METHODS:}

This study was conducted from June 2019 to November 2019 in the Department of Medicine in Geetanjali Medical College and Hospital, Udaipur. Study included 50 adult patients admitted with signs and symptoms suggestive of scrub typhus. Detailed clinical history and clinical examination was recorded. Scrub typhus was diagnosed by enzyme linked immunoassay for scrub typhus. All patients were investigated with complete blood count with peripheral smear, liver and renal function tests, urine analysis, MP-QBC, Dengue serology, blood culture, chest $\mathrm{x}$-ray and Ultrasonography. Pregnant females and patient having other co-infections like malaria, dengue, enteric fever, UTI and septicemia were excluded.

\section{RESULTS:}

Table 1.0-Sign and symptoms at presentation

\begin{tabular}{|c|c|c|c|}
\hline SYMPTOMS & $\begin{array}{c}\text { Number of } \\
\text { patients } \\
(\mathrm{n}=30)\end{array}$ & SIGNS & $\begin{array}{c}\text { Number of } \\
\text { patients } \\
(\mathrm{n}=30)\end{array}$ \\
\hline FEVER < 7 DAYS & $9(30 \%)$ & JAUNDICE & $23(76.6 \%)$ \\
\hline $\begin{array}{c}\text { FERVER 7-14 } \\
\text { DAYS }\end{array}$ & $14(46.6 \%)$ & $\begin{array}{c}\text { LYMPHADENOP } \\
\text { ATHY }\end{array}$ & $19(63.3 \%)$ \\
\hline FEVER > 14 DAYS & $7(23.3 \%)$ & $\begin{array}{c}\text { HEPATOSPLENO } \\
\text { MEGALY }\end{array}$ & $21(70 \%)$ \\
\hline COUGH & $12(40 \%)$ & $\begin{array}{c}\text { ALTERED } \\
\text { MENTAL } \\
\text { STATUS }\end{array}$ & $4(13.3 \%)$ \\
\hline BREATHLESNESS & $24(80 \%)$ & ATAXIA & $2(6.6 \%)$ \\
\hline SEVERE & $20(66.6 \%)$ & ESCHAR & 0 \\
HEADACHE & & NECK RIGIDITY & $4(13.3 \%)$ \\
\hline
\end{tabular}

Fever was present in all patients. Breathlessness was the second most common symptom $(80 \%)$, followed by headache $(66 \%)$ and cough (40\%). The most common sign was jaundice (76.6\%). Lymphadenopathy, hepatosplenomegaly, neck rigidity and ataxia were seen in $63.3 \%, 70 \%, 13.3 \%$ of patients respectively. Eschar was not found in any patient.

Table 2.0 Lab parameters at presentation

\begin{tabular}{|l|l|l|l|}
\hline Investigation & Number of & Investigation & Number of \\
\hline
\end{tabular}
patients $(n=30)$ patients $(n=30)$ 


\begin{tabular}{|c|c|c|c|}
\hline \multirow{3}{*}{$\begin{array}{c}\text { TLC } \\
<4000 \\
4000-11000 \\
>11000\end{array}$} & \multirow{3}{*}{\begin{tabular}{|c|}
$15(50 \%)$ \\
10 \\
$(33.3 \%)$ \\
$5(16.6 \%)$
\end{tabular}} & $\begin{array}{c}\text { SGOT, SGPT (>40 } \\
\text { IU/L) }\end{array}$ & $\begin{array}{c}22 \\
(73.3 \%)\end{array}$ \\
\hline & & $\begin{array}{c}\text { Alkaline Phosphatase } \\
\text { (>130 IU/L) }\end{array}$ & $6(20 \%)$ \\
\hline & & Bilirubin (>1.3mg\%) & $\begin{array}{c}23 \\
(76.6 \%)\end{array}$ \\
\hline \begin{tabular}{|c|} 
Platelet \\
$<1.5 \mathrm{LAC} / \mathrm{CMM}$ \\
$<1.0 \mathrm{LAC} / \mathrm{CMM}$ \\
\end{tabular} & $\begin{array}{c}9(30 \%) \\
21(70 \%)\end{array}$ & $\begin{array}{l}\text { Creatinine } \\
(>1.4 \mathrm{mg} \%)\end{array}$ & $19(63.3 \%)$ \\
\hline Hypocalcaemia & $\begin{array}{c}16 \\
(53.3 \%)\end{array}$ & $\begin{array}{c}\text { Albumin } \\
(<3.0 \mathrm{gm} \%)\end{array}$ & $21(70 \%)$ \\
\hline ELISA POSITIVE & 30 & $\begin{array}{c}\text { Chest X-RAY } \\
\text { INFILTRATES }\end{array}$ & $26(86.6 \%)$ \\
\hline & & $\begin{array}{c}\text { CSF - lymphocytic ple } \\
\text { normal sugar level, } \\
\text { elevated protein and } \\
\text { levels. }\end{array}$ & $\begin{array}{l}\text { ocytosis, } \\
\text { mildly } \\
\text { cised } \mathrm{ADA}\end{array}$ \\
\hline
\end{tabular}

Out of 50 patients, 30 were found to be positive for scrub typhus by ELISA. Thrombocytopenia was present in all patients. Leukopenia was observed in $50 \%$, while leucocytosis was seen in $16.6 \%$ of patients. Hypocalcaemia was noted in $53 \%$ of patients. Liver function was deranged in $76 \%$ of patients. $63 \%$ patients developed acute kidney injury out of which 5 patients required haemodialysis. Albumin was decreased in $70 \%$ of patients. CSF was done in patients with altered mental status which was found to have lymphocytic pleocytosis, elevated sugar, protein and ADA.

Table 3.0 Complications of scrub typhus

\begin{tabular}{|l|l|}
\hline Complications & Number of patients $(\mathrm{n}=30)$ \\
\hline Pulmonary infiltration & $24(80 \%)$ \\
\hline Shock & $14(46.6 \%)$ \\
\hline Renal impairment $>$ l.5MG/dl & $19(63.3 \%)$ \\
\hline Myocarditis & $4(13.3 \%)$ \\
\hline Haemoptysis & $2(6.6 \%)$ \\
\hline Meningitis & $4(13.3 \%)$ \\
\hline Polyserositis & $2(6.6 \%)$ \\
\hline ARF (required haemodialysis) & $5(16.6 \%)$ \\
\hline DIC & $5(16.6 \%)$ \\
\hline
\end{tabular}

Diffuse pulmonary infiltrates were present in $80 \%$ of patients. Acute kidney injury was the second most common complication. Shock was observed in $\sim 47 \%$ of patients. Other complications including myocarditis, meningitis, hemoptysis, polyserositis, disseminated intravascular coagulation were also observed.Discussion: There have been reports of outbreaks of scrub typhus from various parts of the country ${ }^{8}$. In our study out of the 50 suspected cases 30 cases were serologically positive. Patient's presented with acute febrile illness with non-specific sign and symptoms. The most common symptom was fever (100\%), followed by breathlessness (80\%). Most common sign was jaundice (76.6\%). Eschar, the pathognomic sign of scrub typhus was not seen in any patient in our study. Its absence does not rule out scrub typhus.

Scrub typhus was diagnosed by ELISA test for IgM antibody against O.tsutsugamushi. Current serological tests are indirect immunofluorescence, indirect immunoperoxidase and ELISA. Rapid immunochromatography and dipsticks are also available?

Amongst the other lab parameters hepatic dysfunction was most commonly observed in our study. Diffuse infiltrates were seen in Chest x-ray in the lower zone in $80 \%$ of patients. $33.3 \%$ of patients required invasive ventilator support. Renal impairment was the second most common complication observed. 4 patients died in the study. Complication were seen in two thirds of our patients.

1. Traub R, Wisseman CL Jr. The ecology of chigger-borne rickettsiosis (scrub typhus). J Med Entomol 1974;11: 237-303

2. Kasper, D. L. Fauci, A. S., Hauser, S. L. Longo, D. L., Jameson, J. L., \& Loscalzo, J. (2018). Harrison's principles of internal medicine (20 $0^{\text {th }}$ edition). New York: McGraw Hill Education.

3. Wu KM, Wu ZW, Peng GQ, et al. Radiologic pulmonary Findings, clinical manifestations and serious complications in scrub typhus. Experiences from a teaching hospital in Eastern Taiwan. Int J Gerontol2009; 3:197-264.

4. Narendra Rathi, Akanshka Rathi. Rickettsial Infections: Indian perspective, Indian pediatr 2010; 47:157-164.

5. M.Vivekanandan, A. Mani, Y.S. Priya, AJ Singh, S Jayakumar, S. Purty. Outbreak of Scrub Typhus in Pondicherry. JAPI Jan 2010;58:24-28

6. Pathak Praharsh, Mistry abhishek. Pancreatic involvement in scrub typhus. GJRA Feb 2020;2:53-54.

7. Mahajan SK, Bakshi D. Acute reversible hearing loss in scrub typhus. J Assoc Physicians India 2007; 55: 512-14.

8. Mahajan SK, Kashyap R, Kanga A, Sharma V, Prasher BS, Pal LS. Relevance of Weil-Felix test in diagnosis of scrub typhus in India. J Assoc Physicians India 2006; 54:619-21

9. Gurung S, Pradhan J, Bhutia P Y. Outbreak of scrub typhus in the North East Himalayan region-Sikkim: an emerging threat. Indian J Med Microbiol 2013, 31:72-4.)

10. Chrispal, A. Scrub typhus: an unrecognized threat in South India - clinical profile and predictors of mortality. Tropical Doctor. 2010;44(3)

11. Varghese GM, Trowbridge P, Janardhanan I, et al. Clinical profile and improving mortality trend of scrub typhus in South India. Int J Infect Dis 2014; 23:39-43. 